\title{
A ARTE DAS TERRAS ITÁLICAS Uma síntese
}

Dr. Mansueto Kohnen, O.F.M.

Prof. de História das Artes - Rio

INTRODUÇÃO: - Com a dissolução do Império Romano desaparece também a fôrça artística da Itália. Roma, outrora dencminada simplesmente URBS - a cidade - vive qua:a à margem das g:andes criações artísticas da arte românica e gótica, que formaram a essência da Idade Média na Europa. Passam séculos, que encontram a Itália qual terra adormecida. E não tardam a invadí-la as influências forasteiras; celebram seu advento as artes dos povos nórdicos, o reino bizantino, o islamismo, todo o Oriente Médio. As terras Itálicas vivem de saudosismo esteril das brilhantes épocas passadas. Os próprios italianos da Renascença consideraram os séculos do colapso da Antiguidade até Giotto (ca. 1266-1337) uma época de fraqueza interior.

A arte autóctone italiana surge pela primeira vez e de maneira poderosa pelo fim do século XIII. Não houve naturalmente nas fases anteriores uma ausência absoluta de algumas obras belas e até notaveis. Porém, abstraindo deste singularismo, as exceções parecem ser antes modalidades de fuimas extra-italianas de que testemunhos da própria essência italiana. Foram quase esquecidas na coletividade européia. As realizaçōes de Giotto e Niccolo Pis̄ano são, sob o aspecto europeu, inovadoras. Vivificam originariamente a Antiguidade. A inquietude criativa desses dois mestres perpassa todo o "trecento", se bem que não determine o panorama da evolução. Só o século XV introduz a grande fase da plenitude: a Itália torna-se, na Renascença, modelar para todo o Ocidente. A Renascença agonizante, o maneirismo, e o barroco criam grande exuberância de obras magistrais, for- 
mam até a fisionomia de cidades inteiras (p. ex. de Gênova e Roma) e preparam, muitas vezes, o caminho de aspectos novos - mas êstes movimentos artísticos não se arriscam de tirar as últimas deduções estilísticas. A Germânia terá a ousadia de realizar o extremo na última fase do barroco, baseando-se nas realizações italianas, inspirando-se nas corajosas fantasias espaciais de Borromini e Guarini. Os séculos XIX e XX empobrecem novamente e não podem ombrear com a arte francesa e germânica.

\section{OS PRINCIPAIS MESTRES DA ARTE ITALIANA}

Viveram no "trecento", Giotto, ca. 1266-1337 e Niccolo Pisano, ca. 1215/25-1280.

A pintura de Siena conhece Duccio $(+1319)$, Pietro Lorenzetti, que trabalhou por volta de 1303-1348 e Ambrosio Lorenzetti, que se destacou por volta de 1332-1348. Pertencem ainda a esta escola Simone Martini (1248-1344) e Memmi $(+1352)$.

A Pré-Renascença apresenta na arquitetura os trabalhos de Leon Battista Alberti (1404-1472) e Filippe Brumelleschi (1377-1446): no domínio da escultura destacam-se Donatello $(+1446)$, Ghiberti $(+1455)$ e Quercia (1438). Posteriores a eles são Luca della Robbia, Rossellino, Settignano e Verrochio. Sobressaem, na fase pre-renascentista no domínio da pintura, os seguintes: Fra Angelico, Gentile Bellini, Giovanni Bellini, Jacope Bellini, Sandro Botticelli,-Carpaccio, Ghirlandaio, Gozzoli, Fra Filippo Lippi, Mantegna, Masaccio, Perugino e Signorelli.

Brilham, na Alta-Renascença, Bramante (na arquitetura), Correggio, Giorgione, Leonardo da Vinci e Tiziano simultaneamente como escultores e pintores e, afinal, Michelangelo e Raffael em todos os três domínios, sendo que Miguel Ângelo nos deixou também uma série de formosas poesias.

Marcam o fim da Renascença, ou seja o maneirismo, Palladio (na arquitetura) e, na pintura, Bronzino, Parmeggianino, Tintoretto e Tiziano. 
A arquitetura barroca e o rococó viram as criações artísticas de Bernini, Borromini, Juvara, Maderna e Vignola, enquanto mencionamos na pintura os vultos de Canaletto, Caravaggio, Agostino Carracci, Annibale Carracci, Cortona, Guardi, Reni, Rosa e Tiepolo.

\section{EVOLUÇÃO DA ARTE ITALIANA}

Antes de descrevermos a arte italiana propriamente dita, devemos sintetisar sua marcha evolutiva dos séculos VI até XII. A nota característica da evolução da arte italiana é, em geral, sua constância. Desconhece os princípios impetuosos e as surpresas, que marcam a arte germânica.

Assemelham-se, na Itália, as 'construções de vários séculos. Não há diferenças essenciais na construção exterior entre San Lorenzo fuori e Mura (Roma, fim do século VI), San Miniato al Monte (Florença, século XII) e Santa Maria Novella (Florença, século XV).

A variegada arte nórdica, caracterizada pelo cultivo da forma abstrata, penetra, na fase medieva, no sul da Itália, territórios administrados pelos germanos. Os lombardos invadem (em 568) o norte italiano para criar, em contacto com a Antiguidade, uma expressão artística não conforme os cânones desta mesma Antiguidade: preferem a arte linear, privada da escultura e da figura, e a arte do claro-escuro. A arquitectura lombarda da fase românica difere da arquitectura das demais terras itálicas: entraram elementos germânicos e franceses na formação do espaço, na estruturação e no ornamento.

No sul da Itália e na Sicília dominam, desde 1050, os normandos, posteriormente os Hohenstaufen que imprimem à arquitetura exterior suas características a templos e palácios. ostentando, no interior, motivos da arte bizantina e sarracena (p. ex. Palermo, Monreale e Cefalú).

A arte gótica (do norte) é vedada a entrada em terras italianas. Apenas a catedral de Milão conhece uma pálida semelhança com o estilo gótico das catedrais francesas e sua 
modalidade germânica - no fundo, um compromisso, que não satisfaz.

Veneza, Ravena e a Sicília aceitam influência bizantina e islamítica, portanto uma nota oriental, que formou o intei ior da Capella Palatina em Palermo, a arquitetura exterior da igreja (ccm três cúpolas) de San Cataldo, igualmente em Palerno, e a catedra de San Marcos (em Veneza) com as cinco cúpoias e os murais de mosáicos no interior. As núpcias místicas dos mosáicos bizantinos em Ravena estão em pleno contraste com a posterior arte autoctone italiana, que preferira o homem naturalmente belo. Porém, é justamente na base das folmas bizantinas, que a pintura florentina e sienense (do século XIII) trarão o típicamente italiano, sobretudo Giotto e Luccio, aue preparam em muitos tracos a Renascença. O mesmo se dá no domínio arquitetônico.

Porém, mais pode.osa que tôdas as influências do Norte, de Bisância e do Oriente, é a influência da Antiguidade romana, que sempre vivificará a fôrça formal na evolução total da cultura italiana. Assim foi na arte do cristianismo primitivo, assim é até hoje, quando conserva, na arquitetura, a dura linha horizontal, a linha de antigo palácio de justiça e da posterior basílica. Predomina a linha do patriarcado romano, que liquidou o matriarcado dos etruscos. Tôda a estruturação arquitectônica e a divisão mural são claras e racionalmente simples. A Renascença e o barroco conservarão, mais tarde, conscientemente a herança antiga.

Er quanto a gótica ainda domina nas demais terras européias, anuncia-se na arte italiana levemente o renascimento (rinascere, riascità). Depois de 1250 , as terras toscanas estão na vanguarda. Giotto é inovador, anunciando o advento renascentista a pintura da capela de Arena (Pádua, 1305), Pisano cria novas figuras, presas ainda à Antiguidade. Porém, um baquilides de Koos, cantor sacerdotal do século $V$ antes de Cristo, transforma-se em Sumo Sacerdote, Phaidra em Madona. . Transformação idêntica sofre a arquitetura .

Florença assume a hegemonia na fase pre-renascentista. 
Ela aperfeiçoa, na arquitetura, o tipo clássico do palácio cúbico, dando-lhe fisionomia própria, aquilo que, depois, será parcialmente denominado arte lidimamente italiana. Luta, in cialmente, ainda com as linhas irrequietas e incorpóreas da gótica, porém, liberta-se para apresentar, por fim, uma nova e granđiosa forma de beleza terrestre. Os corpos assumem plasticidade completa. Masaccio já lhes dá volume e organismo. Quercia, escultor de mérito e precursor de Miguel Ảngelo, pensa, por assim dizer, em corpos, dando ao relêvo do pecado original em San Petronio (Bologna) tôda a magia dos sentidos e a polaridade forte e corpos que irresistivelmente se aproximam.

Vêm-se as particularidades da vida orgânica, da vida interior do homem individual. As fisionomias mostram seu respectivo t: aço característico e, de quando em vez, se abre ante cs nossos olhos o elemento abismal da personalidade humana, p. ex. ra expulsão dos proto-parentes do paraiso, da autoria de Masaccio. É inesquecivel a figura da Eva desesperada.

Esta arie desconhece o humano. Donatello representa com a mesma alegria, o jovem herói vitorioso e o careca. $O$ lírico figura ao lado do horroroso, o solene ao lado do cotidiano. Triunfam, porém, alegria de vida e beleza soberba. A arte conquista a terra e ela se torna mais antropocêntrica e menos teocêntrica. $\mathrm{E}$ a antiga herança romana ressurge com forte realismo.

A Alta-Renascença, porém, simplifica e harmonisa mais do que a pré-renascenca. Isto se dá menos na arquitetura tradicionalista do que na escultura e pintura, que eliminam mais e mais os detalhes. Raffael oferece plenitude concentrada e dignidade ha:monisada. $O$ ser vence o nascer.

Pouco influem as perturbações da terra. As figuras, quase perfeitas, são claras e importantes. Poucos artistas dinamitaram a cor centricidade da Alta-Renascença, assim o velh Raffael, o já idoso Tiziano, Leonardo, Correggio e sobretudo Mizuel Āngelo. O espaço começa a alargar-se. Sombras indistintzs passam nos murais. Cores ardentes desfazem o equi- 
líbrio. Inquietude e movimentação principiam a viver. E surge, afinal,a problemática da existência — hoje diriamos a insegurança existencialista - na fisionomia da criatura humana.

Os artistas começam na fase do maneirismo - fase de transição entre renascimento e barroco - a alongar as formas. Cabeça, pescoço e mãos são quase naturalmente alongadas. Os corpos ostentam a chamada linea serpentinata. $O$ semblante é estarrecido. As coisas mortas, p. ex. adorno feminino, elmo, couraça, espada de cavaleiros, começam a viver uma vida própria e desligada dos personagens. A maioria dêstes artistas vive do exagero, com exceção de Tintoretto, que se curva reverente ante o fator milagroso da natureza.

A figura extraordinária de Miguel Ângelo parece constituir uma ponte por sôbre os tempos. O grande mestre já participa da pré-renascença, conduz a beleza e dignidade na escultura - à vitória na Alta-Renascença e prepara, avançando corajosamente para o demoníaco e o transcendental, o advento do classicismo. Sua obra gigantesca e inesgotável não desconhece o maneirismo e o barroco. Porém, êle nunca foi "escola" ou apenas "corrente" ou "movimento" artístico, porque seu gênio universalista é demasiado impetuoso, misterioso e excepcional para deixar-se prender nas malhas estreitas do sectarismo. Seus imitadores vêm apenas o extericr e fracassam.

O barroco italiano transforma as linhas harmonisante:s da Alta-Renascença em movimento. Quebra-se, assim, o poder do finito. $O$ homem desta fase quer o desmedido, o infinito. Mas a a:quitetura italiana nega-se às últimas consequências, desviando para uma espécie de classicismo, que retorna (em Juvara) à Alta-Renascença. Este classicismo vence em pleno século XVIII, justamente na época, em que as terras germânicas experimentam o fim das incriveis e novas formulações arquitetônicas de barroco.

A lei da arquitetura italiana é clara: haure da Antiguidade na éra do cristianismo primitivo, conhece a irrupção 
do comedido sentimento antigo no século XIII, favorece o florescimento de um novo classicismo, que tem por afinidade com o antigo na Alta-Renascença e cria, afinal, o elemento classicista com fôrça domadora da passichalidade barroca.

Escultura e pintura apresentam resultados excelentes no quadro e no ornamento, inspirando e fecundando às vêzes até os países vizinhos, sem conseguir superar as produções artísticas da coletividade européia no domínio arquitetônico nem a pintura neerlandesa do barroco com Rubens, Rembrandt e os paisagistas. E assim, o norte europeu recomeça, como na Idade Média, a liderar a arte ocidental.

$O$ rococó experimenta seu auge em Veneza e produz em Tiepolo um novo mestre de pintura. Este envolve a plenitude festiva das figuras nas pinturas de teto e nos murais numa atmosfera luminosa e leve de um céu igualmente luminoso e leve.

Alegram-nos, no século XIX, as pinturas sadias e reverentes de Segantini. E' êle que mais uma vêz sintetisa em seus quadros o sentido e os meios estílicos da arte italiana: sua preferência pelas coisas visiveis e sua paixão pela beleza. Segantini escreve; 'quero em uma única obra "incluir tôdas as belezas, desde as formas até os sentimentos belos, das linhas grandes até às belas, dos belos sentimentos humanos até ao sentido divino da natureza, das belas figuras núas e humanas até às belas formas dos animais, das belas sensibilidades, humanas e modestas, até ao espírito divino dos símbolos, do nascer da lua até ao ocaso o sol, das belas flores até aos campos de neve. Inclino-me ante esta terra abençoada com beleza."

\section{A CIDADE ITALIANA}

A Itália conhece mais do que outras terras o predomínio de certas cidades. Milão, Gênova, Veneza, Pisa, Florença, Siena e Roma são cidades curiosas, por assim dizer: personalidades apreciáveis. Tôdas elas, como Parma, Pistoia e Lucas, têm beleza singular. Desde o início possuem caracte- 
rísticas "citadinas", aversas ao campo e desligadas - em sua fisionomia petrificada — da natureza. A URBS ROMANA continua sua existência em plagas italianas. As cidades germânicas - Nürnberg, Dresden, Rothenburg, Lübeck, Speyer, Mainz, Heidelberg e outras - continuam a mestrar, até hoje, um acento "aldeão", unidas que vivem ao campo e ligadas com a natureza. As cidades italianas têm algo regulamentado e predisposto, as germânicas são irregulares e crescem . Existem naturalmente exceçōes em solo italiano, porém, Florença forma sua fisionomia definitiva e regular na fase dá Renascença, Roma na época entre Renascença e barroco, enquanto Gênova se forma na éra barroca.

Diferentes nāo sāo apenas as fisionomias exteriores, também o horizonte se diferencia. A Itália conhece torres abruptas, horizontais, a Germânia as esbeltas, quase unindo céu e terra. Há tories marcadas por palácios e casas massiças, outras preferem a cúpola harmoniosa - e as mais lindas cúpolas existem em terras itálicas. As germânicas preferem a leveza arquitetônica e gótica.

O mesmo vale das ruas! A Itália conhece a rua reta, o retângulo, a superfície ou a praça aberta, o aspecto cúbico. Tudo, parece obedecer à uma lei preestabelecida e respira quietude. Um grupo de casas e ruas em terras germânicas vivetem movimento, floresce, sobe e desce, atrapalha-se. A Itália conhere também em suas cidades a proporção, a medida, o número, o algarismo, como os conhece no soneto e na canção. Terras germânicas sempre preferiram o verso aliterativo e - ritmo livre. Passando pelas cidades sentimos a sua proporção. As praças, as arcadas e os poços criam pontos de referência e de descanso.

As praças procuram ser amplas e ter vida forte. Ass $r$ : em Siena, Todi ou Sant'Ignazio em Roma. Elas pressupõem o humanismo, que vive clara e firmemente na vida pública, que gosta do gesto livre e amplo, da exteriorização eloquerte e da existência monumental. A praça germânica pede os recantos idílicos, românticos, de intimidade burguesa. A praça 
italiana é ainda um ponto de repouso, recolhe as massas, que a rua apenas deixa passar. Também esvasia rapidamente as praças, como a Piazza del Popolo de Roma. Não raras vêzes são envoltas numa espécie de arquitetura festiva, por exemplo a praça de São Pedro (Roma) ou a praça diante da municipalidade de Siena. $O$ homem, ao passear através as praças, exibe alegremente seu corpo. Quer estar presente, mesmo andando, com todos os seus sentidos. Éle se entrosa no ritmo de ocio. sidade ou movimento, concentraçảo è ação, perambular calm ou tensão nervosa.. As praças não o deixam desinteressar-se da vida à vista da ação incessante.

Também as escadarias italianas se coordenam com a vida bela. Elas não são apenas práticas, mas convidam a parar e apreciar as plataformas entrelaçadas. Tornam o homem vidente e, olhando, aumentam a delícia de ver. Roma possui muitas destas escadarias - São Pedro, a da praça do Capitólio e a espanhola, que se parece com uma escala musical. Quando De Sanctis construiu a escada espanhola (de 1723/6), Bernini posteriormente a ornamentou com o famoso poço "La Barcaccia".

Ai surge mais um aspecto típico e artístico das cidades italianas: o poço. Muitos poços são apenas uma enorme e simples taça e conseguem, graças a esta simplicidade, uma forma perfeita, concordando com a forma de palácios ou a semicircunferência das cúpolas. Mas o descendente dos romanos gosta também do esplendor barulhento das massas aquáticas a jorrar, murmurar e palestrar, como Gertrud von le Fort o descreve logo no princípio de sua abra célebre: "O Sudário de Verônica", cujo primeiro volume se intitula: "O Poço Romano". O poço é, tantas vêzes, o lugar de encontros para conversar, ler ou haurir suas águas frescas. Ele não deixa de ter seu patos, seu entusiasmo, seu aspecto belo e sua frescura para os sentidos. Mas o poço germânico conhece o deslisar sonhador, é o inspirador e autor de contos fabulosos ou enigmáticos, ou afirma ainda, que sob os desvelos de Deus tudo corre bem. Torna-se uma espécie de ser vivo, cheio de bonda- 
de, fidelidade e amizade na existência, como revela a canção: "Am Brunnen vor dem Tore".

$O$ esfôrço da arquitetura das cidades italianas assim se representa: prepara um humanismo, que é vivificado por um mundo alegre, público e seguro, favorecido pelo espaço das ruas e praças para aumentar, em formas simples e claras, as alegrias existenciais. Sublinha a felicidade visual e bereficia o co:po através das disposições rítmicas. Esta arte é guardiā do nobremente natural e de alegria de vida.

\section{O HONEM NA ARTE ITALIANA}

As belas artes têm um papel importantíssimo na vida histórica do povo italiano. Falando da cultura francesa, devemos mencionar, ao lado de sua grandiosa arte arquitetônica e da pintura, as suas produçōes literárias. Na espiritualidade germânica rivalizam filosofia, arte e música, obtendo talvez a última a hegemonia devido à fôrça interior de sua eficiência. A expressão inglesa une o talento político e a vida espiritual para oferecer, assim ,uma parcela essencial de sua fôrça criativa. Porém, o humanismo italiano é enunciado através de uma carta de Catarina de Siena (1347-1380): "O que não se vê, não se pode reconhecer. O que a alma não reconhece, ela não pode amar".

Estas palavras dirigidas ao sacerdote Andrea de Vitroni anunciam a convicção italiana. Confirmam que o dom artístico da Itália se fundamenta na delícia da vista, na paixão; das coisas visiveis.

Visualidade significa presença. Nenhum povo europou consegue nos testemunhos de sua arte uma presença tão continuada de sua História como o italiano. Nápoles e a Sicíliz conhecem templos gregos menos destruidos do que os de Helas. Pompeji continúa a ser a cidade tipicamente antiga. Roma anuncía os feitos de seus imperadores nas portas e nas colunas do triunfo, onde vivem nos relevos também os demais povos da Europa e do Oriente. Na escuridão das catatumbas surge a pureza do cristianismo inicial. As basílicas de Ravena e Rom? 
testemunham fases brilhantes. Os conquistadores - lombardos, normandos e árabes - deixam vestígios. Dante e Giotto começam a formar a italianidade. $\mathrm{E}$ as épocas subsequentes atestam em obras de arte inconfundível na vida pública a concatenação da História dêste povo.

Além da presença continuada da sua História, a arte das terras itálicas conhece ainda a presença continuada da arte romana. Ela formou seu poder visual e despertou atitudes espirituais afins. Como os feitos romanos foram marcados com grande realismo nos carros de triunfo, assim, êste mesmo realismo volta nos relêvos de Giotto, Masaccio, Mantegna e Ghirlandaio, nas esculturas de Donatello e Verrocchio e ainda no "portrait" italiano. Vive na arte italiana o sentido romano das formas grandes nos monumentos, palácios, poços e escadarias. A inspiração romana de poderio e formas senhoriais não entra só na arquitetura, pois a pintura não despreza disposições grandes e claras, como os frescos de Giotto em Pádua e a "Escola de Atenas" de Raffael.

Considerando êstes fatôres, verificamos que a Itália criou também uma típica arte do homem! Onde quer que a arte italiana se encontre com a criatura humana, sempre o fa2 festivamente, mostrando nela o brilho e a grandeza, convencida que é uma distinção inefável possuir fisionomia humana. O corpo humano merece atenção especialíssima em tôdas as suas movimentações, como já vemos nas obras de Giotto. $O$ elemento corpóreo é um tema fundamental da arte italiana. Ghirlandaio, por exemplo, enche um quadro todo para demonstrar os dois movimentos: - andar e ficar parado, Gozzoli para exemplificar o levantar de uma cesta ou o carregar de uma fruteira, Tiziano ou Giorgione para apresentar a escritura clara de um corpo nú em descanso ou o entrosamento dos membros. Como se diferenciam as duas representações de Anna Selbdritt, uma italiana, visual, da autoria de Leonardo, a outra, nórdica, espiritual, da escada flamenga. A atividade de Miguel Ângelo é vivificada pela paixão de representar corpos para, assim, enunciar as emoções de sua grande alma 
enigmática. Só dedicada ao corporal, a arte italiana esquece. muitás vêzes, a expressão espiritual.

O nórdico quer ver no corporal mais do que o simples corpóreo: êle é apenas a fôrça visível da alma, pois, o corpo encerra valor definitivo ou importante. Pinturicchio e mesmo Raffael - na "Escola de Atenas" - devem ser compreendidos como artistas do corpóreo.

Livre e belo desdobra-se o jôgo na nudez. O nú masculino e feminino são temas básicos na atividade de quase todos os mestres da arte italiana. A alegria do nú predomina, até no motivo de São Sebastião na coluna, como ainda nas obras de Donatello e Lucca della Robbia nos coretos dos cantores na catedral de Milão. Ou vejamos Miguel Ângelo: vive esta mesma atitude do quadro da Sagrada Família e no teto da Capela Sixtina em Roma, pois as sibilas e os profetas são rodeados de jovens nús que - dominados apaixonadamente por fôrças demoníacas - representam o orgulho e a perdição do homem no e pelo corpo. O nú italiano abrange o sublime e o solene, o leve e o jocoso. Mesmo as pessoas vestidas deixam transparecer o corpo nú. Raffael não repudia esboçar o nú para representar a Madona ou Cristo para ser exato e porque respeita a vida orgânica da criatura humana.

A alegria corporal da arte italiana não é frívola nem anti-espiritual. E' diferente da nudez catita do rococó francês. Não se escraviza à insensibilidade carnal, mas solve os corpos através da forma clara e firme, da pureza e música das linhas, procurando aquela beleza que espirituliza o sensual, e o espiritual que reluz no brilho sensual. Leone Battista Alberti considera "qualquer ação humana, que seguiu de alguma maneira à lei da beleza, quase alvo divino." Mesmo a velhice é apreciada sôbre aspecto da beleza. Desconsiderando feiura ou decadência, representam-na Bellini, Raffael, Tizian e Tintoretto. São anciãos nobres aos quais se poderia aplicar a descrição de Petrarca à vista do Stefano Colonna de 86 anos de idade (ca. 1350): "Deus bondoso, que homem majestoso! Que 
voz, que frente, que semblante, que figura! Como é vivo o seu espírito, como é forte ainda com esta idade!"

A arte das terras itálicas adorna sobretudo a figura da Madona com mocidade e pormosura, encantos e graça. As Marias de Fra Filippe Lippi não são insensíveis, fechadas ou espiritualizadas. Não possuem sentimentos profundos, mas o encanto da pele morena, das faces, das mãos finas e compridas, do pescoço nobre e delgado. A beleza corpórea penetra, na arte italiana, até ao céu. Raffael e Leonardo emprestam aos anjos juventude e beleza. Fra Angelico e Gozzoli interpretam as alegrias do céu partindo da Charis (graça interior) dos anjos. Esta arte ainda sabe: Deus é também beleza, é a beleza e, à vista de transformação de tudo no fim do mundo, quando tudo se renova e os corpos ressuscitarão transfigurados, representa o céu qual mar de flores de glórias celestiais, onde vivem anjos semelhantes a donzelas cheias de juventude pura e imperecível. A arte germânica contrasta: Grünewald dá ao anjo no altar de Isenheim aspecto ameaçador, Veit Stoss lhe empresta em (Nürnberg) fôrça terrível em gestos e olhares e Lochner sabe de anjos meigos e sonhadores.

A arte italiana aferrolha o homem contra o sonho e a distância indeterminada. "O que não se vê, não se pode reconhecer. O que a alma não reconhece, ela não o pode amar" (Catarina de Siena).

Poderíamos ainda recordar um dos efeitos mais importantes da arte italiana: a presença de sua História qual eco da antiga alegria de ganhar glória imortal. Alberti o confirma: "A pintura contém uma fôrça verdadeiramente divina. Consegue não só tornar presente, como a amizade, homens distantes, ms consegue ainda que os mortos após muitos séculos ainda parecem vivos."

Não há outro povo europeu que tivesse favorecido e desenvolvido os fatos ou personagens históricos com tal intensidade através de verdadeiros monumentos ou quadros históricos. E acontece que os triunfos atestam novamente a se- 
gurança mundial e a alegria corporal dos italianos, em que Roma jamais está distante, quando descrevem os feitos de um herói, do amor, da castidade ou da religião.

Basta, para comprovar estas asserções, citar um único exemplo: Petrarca e seus "Trionfi", escritos entre 1357 e 1374. 4 cantos são dedicados ao triunfo do Amor, 3 à Morte, um ao triunfo da Castidade, um ao Tempo e um à Divindade. Petrarca fala, nestes 12 triunfos, de seis temas, porém, Amor e Fama formam o âmago. Verdade é que o Amor e Fama são superados pela Morte e pelo Tempo, mas conservam seu valor na face de Deus. No triunfo de Amor e Morte reluz a proximidade da arte antiga, para a qual o homem é a medida de tôdas as coisas. Petrarca conseguiu nestes seis temas e triunfos, que poderiam aparentar disarmonia, uma harmonia excepcional: Castidade e Amor enchem este mundo com brilho - a Morte perde, porém, seu terror à vista da Fama. $\mathrm{E}$, assim, a arte das terras itálicas consegue perpetuar a presença de sua História qual eco da antiga alegria de ganhar glória imortal.

\section{FORMAS DE COMPOSIÇÃO DA ARTE ITALIANA}

Lützeler, o exímio historiador das artes, que nos forneceu os elementos essenciais deste ensaio, afirma que a arte italiana procura:

a) - $u$ espaco claro e firme. Proteje o homem e o objeto do ilimitado, sublinhando a grandeza do assunto representado, mormente na arquitectura.

b) - esta clareza e firmeza arquitetônicas prevalecem também na representaçāo da natureza, preferindo a proximidade à distância. Falta o elemento das florestas imensas e das neblinas ondulantes. Ela "constroi" paisagens.

c) - não cultiva o elemento humano separado de outros seres (humanos), representando o grupo com singular maestria, como vemos no motivo da "Santa Conversazione". 
d) - movimentos livres e beleza viva não excluem para os mestres (Giotto, Masaccio e Raffael) a aplicação de regras firmes e geométricas.

e) - a arte italiana respira, em sua maneira de composição, sossêgo e quietude na maioria de suas criações artísticas.

\section{LIMITES DA ARTE ITALIANA E SUA SUPERAÇĀO}

Leonardo da Vinci escreve certo dia: "Não vês, que a vista abrange tôda a beleza do mundo inteiro?! Ela é a cabeça da astronomia, executa a cosmografia, aconselha e corrige tôdas as artes humanas. Impeie cs homens para os mais diferentes quadrantes do mundo. $\overline{\mathbf{E}}$ a guia das disciplinas matemáticas, suas ciências são extremamentes exatas. Mediu altitude e magnitude das estrelas, encontrou os elementos e sua posição e mandou predizer as coisas vindouras do curso dos astros; gera a arquitetura e a perspectiva e, afinal, a pintura divina. $O$ vista sumamente distinguida, criada por Deus acima de tôdas as coisas! Quais os elogios que conseguem enunciar tua nobreza? Quais os povos e línguas que podem descrever exaustivamente tua atividade como e'a é? E a janela do corpo humano através da qual a alma vê a beleza do mundo para gozá-la e por causa dela se deixa prender no cárcere do corpo humano e este cárcere seria uma tortura sem ela."

Este hino cantado à vista está ligado à visualidade das produções mais lindas da arte italiana. Tal incondicionalidade do hino não consegue silenciar a dúvida, se um sentido, cultivado com clareza e medida, abarca a realidade tôda inteira? Em outras palavras: que diz a arte italiana sôb:e a existência do mal no mundo, que torna problemática tôda e qualquer harmonia do mundo? que diz do elementar, que rompe tôdas as fronteiras? que diz do misterioso no homem, em tôrno do homem e acima do homem? Tudo isto foge, tantas vezes, à nossa vista ou visão perceptível, ao registro da retina! A arte italiana esquiva-se ou desvia, em geral, das 
comoções horrorosas. Poucas vezes avança até os domínios rnenos claros e firmes.

O problema do mal ressurge com tôda a sua expressão destruidora na Paixão do Cristo. A arte das terras itálicas - em comparação com a germânica - a representa poucas vêzes. Quando a representa, fá-lo com discreção, procurando diminuir o acento trágico: Cristo é belo, ainda na cruz; também a paisagem e os homens continuam numa atitude natural, como prova uma comparação entre a Pietà italiana e germânica.

Existem ainda os mesmos contrastes graves na representação do elementar, se comparamos as obras artisticas de Grünewald com as de Leonardo, Corregio e Caravaggio. Os últimos procuram sempre a suavidade sensual e a plenitude do fator visivel.

E vejamos ainda a arte religiosa em terras itálicas, aquela que diz respeito ao misterioso. Também esta prefere o acento luminoso e meigo. Deus não é, para ela, o Deus Todo-Poderoso, o Incompreensível, que provoca um santo temor. Não é o Inefável e o Inominável, pois, Ele é o Pai de todos, cuja casa é para todos. Seu amor abraça a todos, Sua grandeza não atemoriza. Esta atitude da piedade italiana determina igualmente sua arte. Muitos quadros religiosos são em seus motivos, absolutamente profanos. Muitos agradecem, em pura alacridate mundana, ao Criador o presente grandioso do mundo. Piedade e beleza natural não constituem contrastes. Aqui predrmin tamhém a "anima naturaliter pia."

Essa atitude ante o mal, o elementar e misterioso-religioso poderia facilmente tornar o ambiente, os homens e, em particular, os artistas indivíduos superficiais. Porém, a Itália conheceu, de vez em quando, através de personalidades excepcionais, a decisão espiritual. Não no sentido da decisão religiosa da arte espanhola, que neste particular é inexcidivel em terras européias. Sua decisão espiritual se personalisa em poucos, porém, marcantes tipos.

Savonarola força a cidade de Florenza, enamorada em 
sua beleza, à decisão religiosa. Francisco de Assis, o p̈oetá, cantor e santo, opõe à segurança temporal e ao fausto de sua época a pobreza radical e a simplicidade alegre. Tomás d'Aquino e Boaventura abrem os abismos dos mistérios divinos numa linguagem nova, distante e diferente do latim sóbrio e prático da antiga Roma. Dante - o poeta simplesmente - é exceção e, ao mesmo tempo, auge da poesia italiana e ocidental.

Aqui e acolá surgem mestres, que inquietam fecundamente a bela humanidade e harmonia terrestre da forma. Bellini e Mantegna representam a disarmonia do feio e a tortura da morte. Botticelli - influenciado por Savonarola peca às vezes contra a tradicional beleza. E Leonardo conhece enorme polaridade interior, quando cria figuras de beleza mui macia e, ao mesmo tempo, caretas de extrema feiura e corrupção. Os frescos de Signorelli na Catedral de Orvieto não ignoram as visões do Anti-Cristo, o incêndio mundial - como o "Muspilli" da literatura arcáico-germânica e o horror infernal.

E surge, finalmente, Miguel Ângelo, italiano em sua alegria à vista da aparência escultural-sensual, e - italiano (já para os seus contemporâneos) em sua "terribilità" nas pinturas da Capela Sixtina, quando representa ritmos selvagens dos condenados ou paisagens terrificantes do inferno ou ainda o caos e anarquia fervescentes das fôrças elementares e telúricas. Pois, Miguel Ângelo talvez seja o único dos grandes artistas italianos, que se emociona ante o mistério do religioso em suas poesias, esculturas e pinturas. Ele vê tudo numa visão transcendental e universal: o mundo, criado por Deus da proto-matéria; o mundo apóstata. castigado pela fúria divina; a criatura humana soberba, entrando - graças à mão criadora de Deus! - na magia do pecado ou da graça, realizando seu destino ou na ausência de Deus ou na fidelidade a Deus. O olhar de Miguel Ångelo não apenas vê, mas perscruta seu ouvido não só percebe, mas ausculta vozes transcendentais. E' comovente contemplar sua Pietà Rondanini, incompleta, que sentiu o cinzel de ancião de 90 anos ainda 
três dias antes da visita da irmã morte: o cadaver de Cristo está erguido, quase de pé, e nesta atitude da vida experimenta a fôrça da morte, que transforma a Mãe das Dores em pedra e coluna. Esta Pietà nega e rejeita as demais formas da arte italiana, a saber: simplicidade, naturalidade e beleza. O humano limitado perde sua validade ante a profundeza mística do religioso. Atitude mística semelhante vemos em Giotto na morte de Cristo e em Botticelli na festa do Natal, quando anjos e homens se abráçam à vista da união de céu e terra.

Tôdas estas obras ampliam e alargam excepcionalmente os limites da demais arte italiana, fecundando-a intensamente. Pois, ela prefere, em geral, a bela e natural humanidade.

Onde a arte italiana termina, aí principia a arte germânica. A Itália procura a terra, em que vivemos, desconhecendo, quase sempre, um meditar aprofundado sôbre os símbolos do sobrenatural.

\section{BIBLIOGRAFLA:}

SEGANTINI: Schriften und Briefe. Zuerich 1935, p 92s. - VINCI, LEOnardo dä: Das Buch der Malerei. Wien 1882, p. 31 - LUEZELER: Die Kunst der Voelker. Freiburg, 1954, passim. - Idem: Fuehrer zur Kuns:. Ibid. 1953. - Idem: Die christlichleiche Kunst des Abendlandes. Bonn, 1950. KOHNEN: Giotto, inovador da arte cristā na Idade Média, in: A Ordem. Rio de Janeiro 1938, 309-316. - Idem: A arte das terras germânicas - uma sintese, in: Intercâmdio XII (1955) n. $.^{4} / 6,44-53$. São Paulo. - Idem: Visão panorâmica da arte espanhola, in: Letras. Curitiba. N. 5 e 6, 1956, 10-17. - SCHMIOT: Geschichte der modernen Malerei. Stutgart, 1952. - MAGNE: L'Art dans L' Antiquitè. Paris (S. A.) - MUESELER: Die Kunst der Welt. Berlin 1954. - BAUCH: Abendlän dische Kunst, Düsseldorf 1952. - HAMANN: Geschichte der Kunst. Vol. I., Muenchen 1952. - MUESEICER Europaeische Malerei. Berlin 1952 - Muche: Buon Fresco. Briefe aus Italien ueber Handwerk und Stil der echten Freskomalerei. Tuebingen 1950. - KATHARINA VON SIENA: Briefe, Berlin 1919, 31. - Schaffran: Die Kunst der Longobarden in Italien.

Jena 1941. - WETGELT: Die sienesische Malerei des 14. Jahrhunderts. Firenze-Muenchen 1930. - NICCO: Jacopo della Quarcia. Firenze 1934. - Tolnay: Michelangelo. 3 vols. Princeton 1945-48. - ALBERTT: Kleinere kunsttheoretische Schriften. Edit. Janitschek. Wien 1877. 